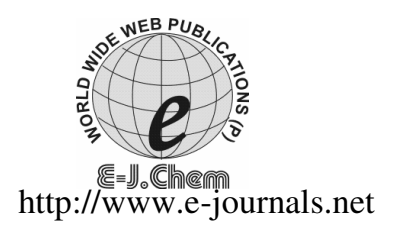

ISSN: 0973-4945; CODEN ECJHAO

E-Journal of Chemistry

2011, 8(2), 882-886

\title{
Evaluation of Antioxidant Activity of Medicinal Plant Extracts Produced for Commercial Purpose
}

\author{
A. D. SATHISHA*, H. B. LINGARAJU and K. SHAM PRASAD \\ Bio-Medicinal Research Laboratory, Vidya Herbs Pvt. Ltd \\ Jigani Industrial Area, Bangalore, India \\ sathishabiochem@yahoo.co.in
}

Received 28 April 2010; Accepted 17 July 2010

\begin{abstract}
The antioxidant potential of some herbal plant extracts (commercial products) was measured using various in vitro assays. Among the extracts from Curcuma longa, Caffea arabica, Tribulus terrestris, Bacopa monnieri and Trigonella foenum- graecum, the Curcuma longa and coffee bean extract (Caffea arabica) showed greater antioxidant activity measured as scavenging of DPPH, superoxide radicals, reducing power and inhibition of microsomal lipid peroxidation.
\end{abstract}

Keywords: Extract, Free radical, Antioxidant activity, Medicinal plant.

\section{Introduction}

The many number of medicinal plants are used in the cellular and metabolic disease treatment such as diabetes, obesity and cancer etc. There are some speculations that the generation of free radicals inside the body in some physiological conditions is resulted in the cellular changes and development of cancer etc. and this could be neutralized by the antioxidants from different medicinal plants. Several studies have shown that plant derived antioxidant neutraceuticals scavenge free radicals and modulate oxidative stress-related degenerative effects ${ }^{1,2}$. Free radicals have been implicated in many diseases such as cancer, atherosclerosis, diabetes, neurodegenerative disorders and aging ${ }^{3,4}$. Previous research reports suggest that higher intake of antioxidant rich food is associated with decreased risk of degenerative diseases particularly cardiovascular diseases and cancer ${ }^{5}$.

The free radical neutralizing property of several plants was reported by previous studies. The extracts from number of medicinal plants which are known to have some biologically active principles are used in ayurvedic preparations and these extracts are prepared in bulk for commercial purpose. In this present study we have measured antioxidant activity of various extracts like Curcuma longa, Coffee bean extract (Caffea arabica), Tribulus terrestris, Bacopa monnieri and fenugreek (Trigonella foenum graecum) employing various in vitro assay methods, such as scavenging activity of DPPH, superoxide radical, inhibition of microsomal lipid peroxidation and reducing power. 


\section{Experimental}

Nitroblue tetrazolium (NBT), 1,1-Diphenyl-2-picrylhydrazyl (DPPH), Phenazine methosulphate (PMS), Butylated hydroxylanisole (BHA), Thiobarbituric acid (TBA), Bovine serum albumin (BSA), Ethylenediaminetetraacetic acid (EDTA) were purchased from HiMedia Laboratories and S. D. fine chemicals, Mumbai, Nicotinamide adenine dinucleotide-reduced (NADH), Trichloroacetic acid, Deoxyribose, Ascorbic acid and other chemicals were procured form Sisco laboratories, Mumbai. All the reagents were analytical grade and UV-Visible spectrophotometer, 1800-Shimadzu.

\section{Preparation of herbal extracts}

The above said herbs were selected and procured from the approved supplier. They were washed with water and then powdered. The powder was taken and extraction was carried out in large scale capacity reactor using $75 \%$ methanol and concentrated. The concentrated extract was spray dried and the dried powder was taken to check the antioxidant activity.

\section{DPPH radical scavenging assay}

DPPH radical scavenging activity was done using the reported method ${ }^{6}$; the reaction mixture containing $1 \mathrm{~mL}$ of DPPH solution $(0.1 \mathrm{mmol} / \mathrm{L}$, in $95 \%$ ethanol v/v) with different concentrations of the extract was shaken and incubated for $20 \mathrm{~min}$ at room temperature and the absorbance was read at $517 \mathrm{~nm}$ against a blank. The radical scavenging activity was measured as a decrease in the absorbance of DPPH and calculated using the following equation:

Effect of scavenging $(\%)=\left[1-\mathrm{A}_{\text {sample }(517 \mathrm{~nm})} / \mathrm{A}_{\text {control }(517 \mathrm{~nm})}\right] \times 100$

\section{Superoxide radical scavenging assay}

The superoxide radical scavenging activity of the extracts was measured according to the literature method $^{7}$. The reaction mixture containing PMS $(0.1 \mathrm{mmol} / \mathrm{L}), \mathrm{NADH}$ $(1 \mathrm{mmol} / \mathrm{L})$, NBT $(1 \mathrm{mmol} / \mathrm{L})$ in phosphate buffer $(0.1 \mathrm{~mol} / \mathrm{L}, \mathrm{pH} 7.4)$ with different concentrations of the extract was incubated at room temperature for $5 \mathrm{~min}$ and the color was read at $560 \mathrm{~nm}$ against a blank. The scavenging effect was calculated using the following equation:

$$
\text { Effect of scavenging }(\%)=\left[1-\mathrm{A}_{\text {sample }(560 \mathrm{~nm})} / \mathrm{A}_{\text {control }(560 \mathrm{~nm})}\right] \times 100
$$

\section{Inhibition of microsomal lipid peroxidation}

Liver excised from adult male Wister rats, was homogenized $(20 \mathrm{~g} / 100 \mathrm{~mL}$ tris buffer $)$ in $0.02 \mathrm{~mol} / \mathrm{L}$, tris buffer $(\mathrm{pH}$ 7.4). Microsomes were isolated by the calcium aggregation method $^{8} .100 \mu \mathrm{L}$ of liver microsomal suspension $(0.5 \mathrm{mg}$ protein) was incubated with $1 \mathrm{mmol} / \mathrm{L}$ each of $\mathrm{FeSO}_{4}$ and ascorbic acid with or without extract in a total volume of $1 \mathrm{~mL}$ in $0.1 \mathrm{~mol} / \mathrm{L}$ phosphate buffer ( $\mathrm{pH} 7.4)$. After incubation at $37^{\circ} \mathrm{C}$ for $60 \mathrm{~min}$, TBA $(0.67 \mathrm{~g} / 100 \mathrm{~mL}$ water) was added to the reaction mixture and boiled for $15 \mathrm{~min}$. The TBA reactive substances (TBARS) was calculated from the absorbance at $535 \mathrm{~nm}^{9}$ where BHA was used as the positive control.

\section{Measurement of reducing power}

The extracts were taken in different concentrations in phosphate buffer $(0.2 \mathrm{~mol} / \mathrm{L}, \mathrm{pH} 6.6)$ and incubated with potassium ferricyanide $\left(1 \mathrm{~g} / 100 \mathrm{~mL}\right.$ water) at $50{ }^{\circ} \mathrm{C}$ for $20 \mathrm{~min}$. the reaction was terminated by adding TCA solution $(10 \mathrm{~g} / 100 \mathrm{~mL}$ water $)$, centrifuged at $3000 \mathrm{rpm}$ for $10 \mathrm{~min}$ and the supernatant was mixed with ferric chloride $(0.1 \mathrm{~g} / 100 \mathrm{~mL}$ water), the absorbance measured ${ }^{10}$ at $700 \mathrm{~nm}$. The increased absorbance of the reaction mixture indicated increased reducing power. 


\section{Results and Discussion}

Extracts were subjected for the evaluation of antioxidant activity by using various in vitro model systems. DPPH radical scavenging activity was observed in all the extracts, the curcuma extract showed dominant activity followed by coffee bean extract (Figure 1) among the extracts. The $\mathrm{IC}_{50}$ values were calculated and are depicted in (Table 1).

Table 1. $\mathrm{IC}_{50}$ values of the respective extracts in different in vitro models. Each values represents $\mathrm{SD} \pm$ mean $(\mathrm{n}=3)$

\begin{tabular}{cccc}
\hline \multirow{2}{*}{ Extract } & \multicolumn{3}{c}{$\mathrm{IC}_{50}$ in $\mathrm{mg} / \mathrm{mL}$} \\
\cline { 2 - 4 } & $\begin{array}{c}\text { DPPH radical } \\
\text { scavenging activity }\end{array}$ & $\begin{array}{c}\text { Super oxide radical } \\
\text { scavenging assay }\end{array}$ & $\begin{array}{c}\text { Inhibition of microsomal lipid } \\
\text { peroxidation assay }\end{array}$ \\
\hline C. longa & $0.32 \pm 0.12$ & $0.4 \pm 0.14$ & $0.37 \pm 0.10$ \\
C. arabica & $0.40 \pm 0.23$ & $0.52 \pm 0.18$ & $0.42 \pm 0.11$ \\
T. terrestris & $0.65 \pm 0.11$ & $0.70 \pm 0.22$ & $0.61 \pm 0.06$ \\
B. monnieri & $0.73 \pm 0.09$ & $0.76 \pm 0.02$ & $0.72 \pm 0.22$ \\
T. foenum & $0.81 \pm 0.21$ & $0.79 \pm 0.32$ & $0.80 \pm 0.12$ \\
\hline
\end{tabular}

Proton radical scavenging action is an important attribute of antioxidants, which is measured by DPPH radical scavenging assay. Hydrogen donating ability of the antioxidants molecules contributes to its free radical scavenging nature.

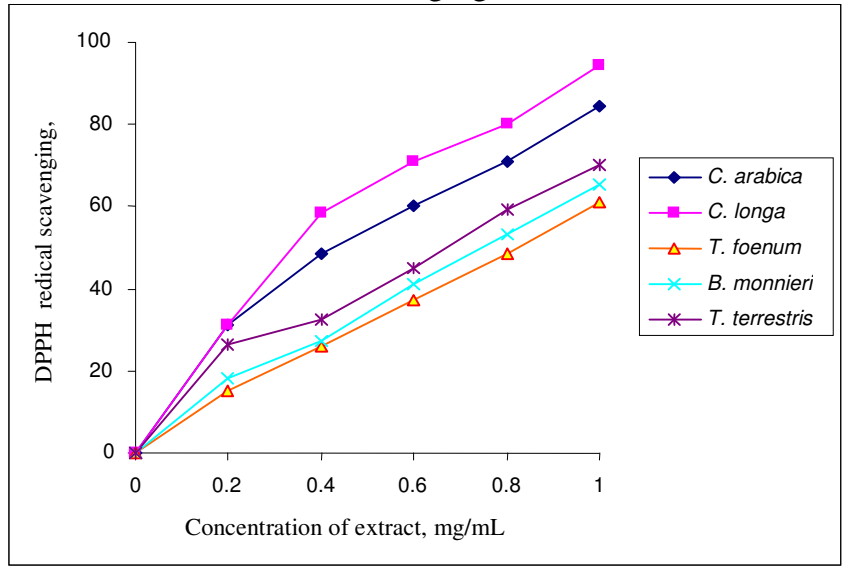

Figure 1. DPPH radical scavenging assay data represents, mean \pm SEM, for $n=3$

Superoxide radical scavenging activity was shown by both curcuma and coffee bean extracts and was concentration dependent with an $\mathrm{IC}_{50}$ value of $0.4 \pm 0.14$ and $0.52 \pm 0.18 \mathrm{mg} / \mathrm{mL}$ respectively (Table 2 and Figure 2). Curcuma extract was markedly a more potent scavenger of superoxide anion than the CBE followed by the others.

As shown in Figure 3 Curcuma extract showed dominant activity followed by CBE, whereas, less activity was observed in case of methi extract. All the extract showed antioxidant activity in concentration dependent manner.

It had been broadly defined as the oxidative deterioration of polyunsaturated lipids. Initiation of a peroxidation sequence in a membrane or polyunsaturated fatty acid is due to abstraction of a hydrogen atom from the double bond in the fatty acid. The free radical tends to stabilized by a molecular rearrangement to produce a conjugated diene. This reacts with oxygen molecule to give a peroxy radical. Peroxy radical can abstract a hydrogen atom from another molecule to give lipid hydro peroxide. 


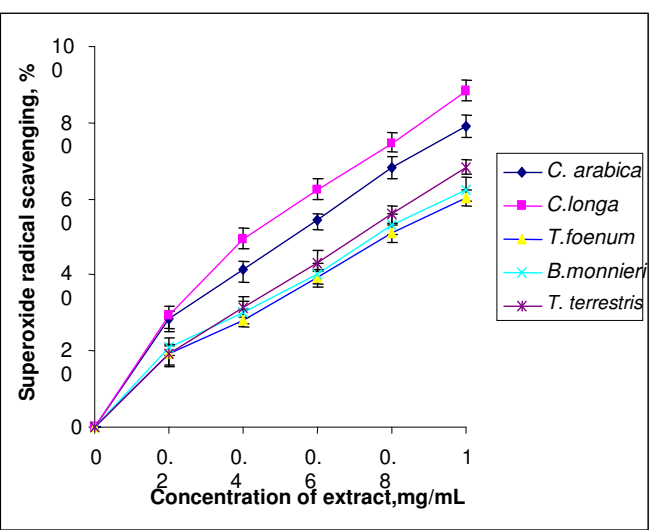

Figure 2. Superoxide radical scavenging activity data represents, mean \pm SEM, for $n=3$

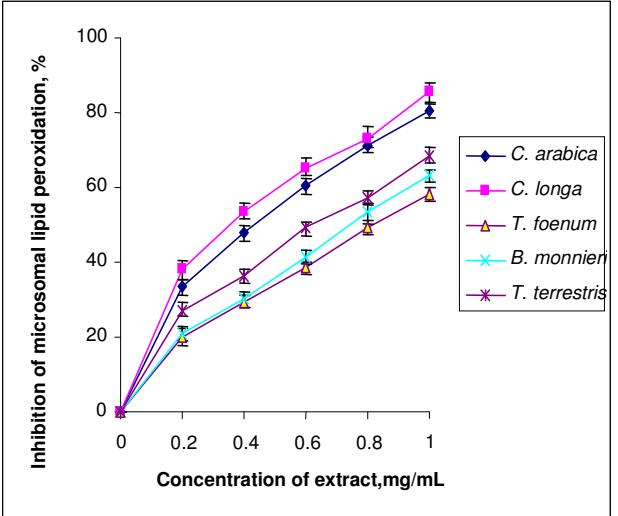

Figure 3. Inhibition of microsomal peroxidation data represents, mean \pm SEM, for $\mathrm{n}=3$

The reducing power of different commercial extracts was performed and showed concentration dependent manner (Figure 4). Curcuma extract exhibits good reducing power activity among five extracts. It is believed that antioxidant activity and reducing power are related. Reductones inhibits LPO by donating a hydrogen atom and thereby terminating the free radical chain reaction.

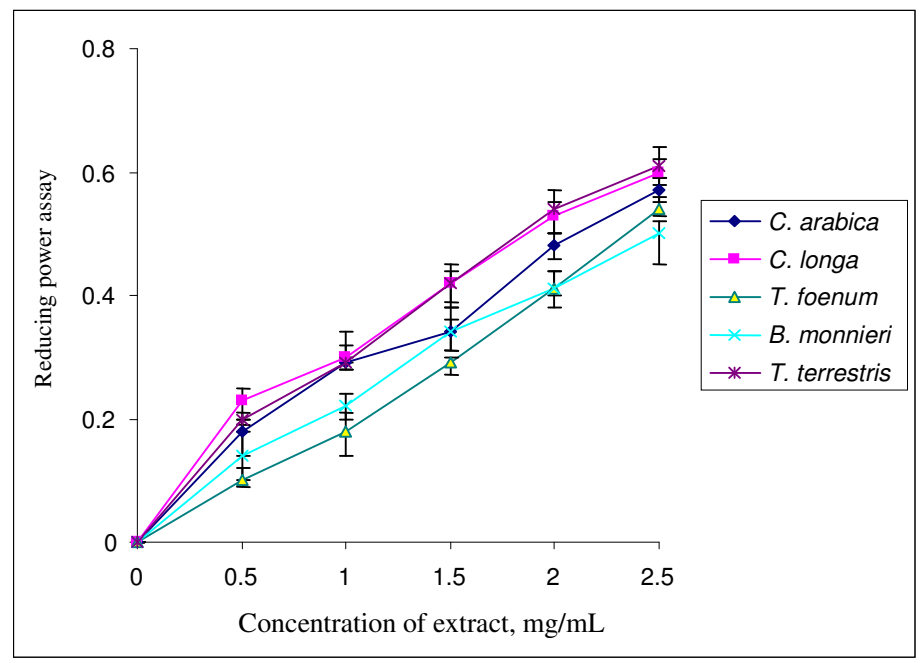

Figure 4. Reducing power assay data represents, mean \pm SEM, for $n=3$

\section{Conclusion}

In order to characterize antioxidant activity of a plant extract, it is desirable to subject it for the tests that evaluate the range of activities such as scavenging of the reactive oxygen species, inhibition of membrane LPO and metal ion chelation. Antioxidant-rich plant extracts serves as sources of nutraceuticals that alleviate the oxidative stress and therefore prevent or slow down the degenerative diseases. An effort has been made to explore the antioxidant properties of commercial available herbal extracts. This indicates the potential of 
the extracts as a source of natural antioxidants or nutraceuticals with potential application to reduce oxidative stress with consequent health benefits.

\section{References}

1. Ames B N, Shigenaga M K and Hagen T M, Acadamy of Sciences of the United States of America, 1993, 90, 7915-7922.

2. Joseph J A, Shukitt-Hale B, Denisova N A, Bielinski D, Martin A, McEwen J J and Bickford P C, J Neurosci., 1999, 19(18), 8114-8121.

3. Halliwell B and Gutteridge J M, Oxford: Oxford University Press, 1999.

4. Yu B P, Physiological Rev., 1994, 76, 139-162.

5. Thatte U, Bagadey S and Dahanukar S, Mole Cellular Biochem., 2000, 46, 199-214

6. Yamaguchi T, Takamura H, Matoba T and Terao J, Biosci Biotechnol Biochem., 1998, 62, 1201-1204.

7. Nishikimi M, Rao N A and Yagi K, Biochem Biophys Res Commun., 1972, 46, 849-864.

8. Kamath S A and Rubin E, Biochem Biophys Res Commun., 1972, 49, 52-59.

9. Buege J A and Aust S D, Microsomal Lipid Peroxidation Methods in Enzymology, 1978, 52, 302-310.

10. Yen G C and Chen H Y, J Agricultural Food Chem., 1995, 43, 27-32. 


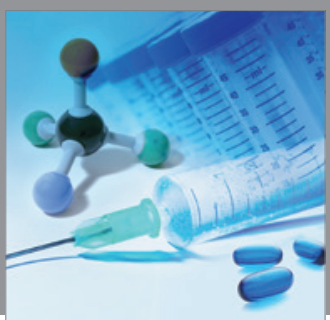

International Journal of

Medicinal Chemistry

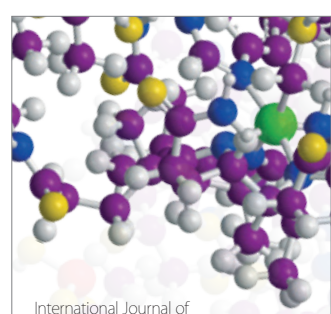

Carbohydrate Chemistry

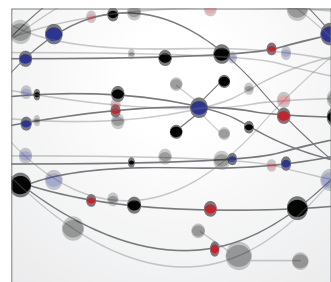

The Scientific World Journal
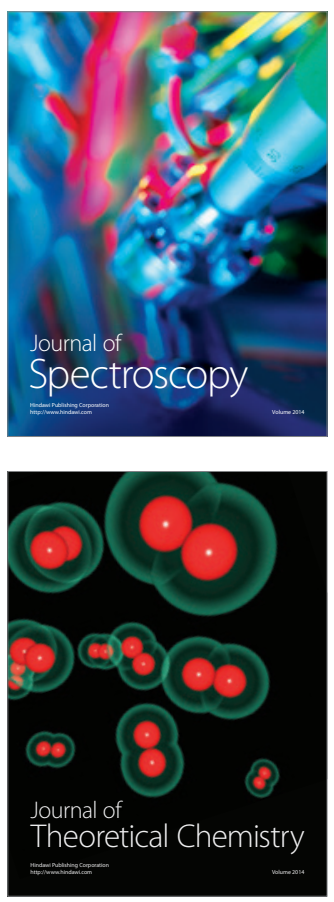
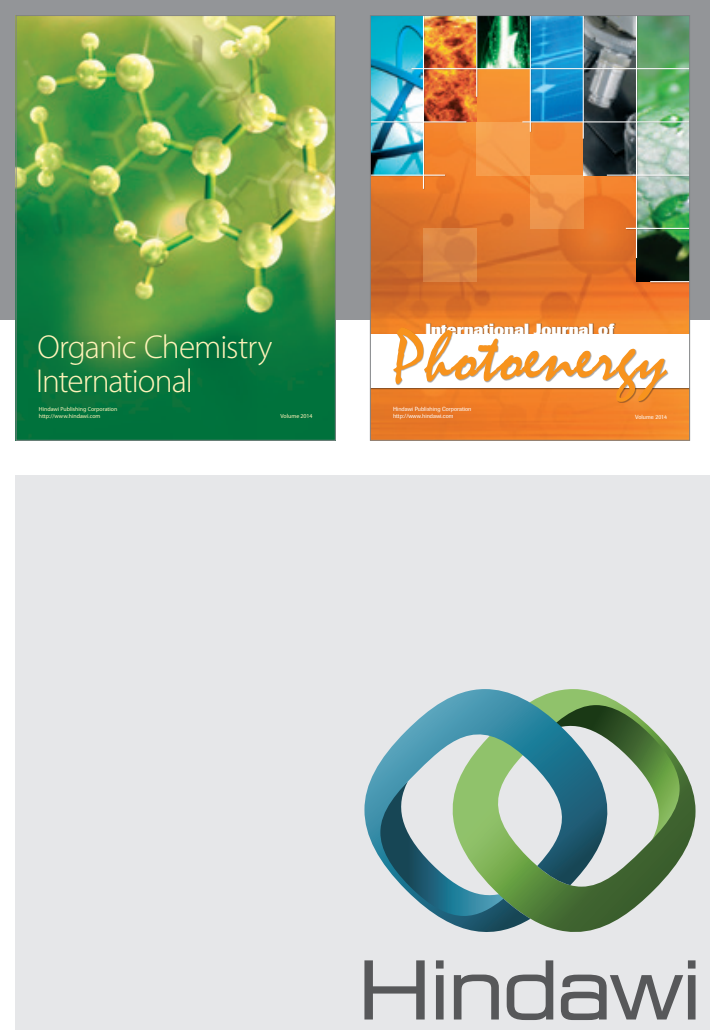

Submit your manuscripts at

http://www.hindawi.com
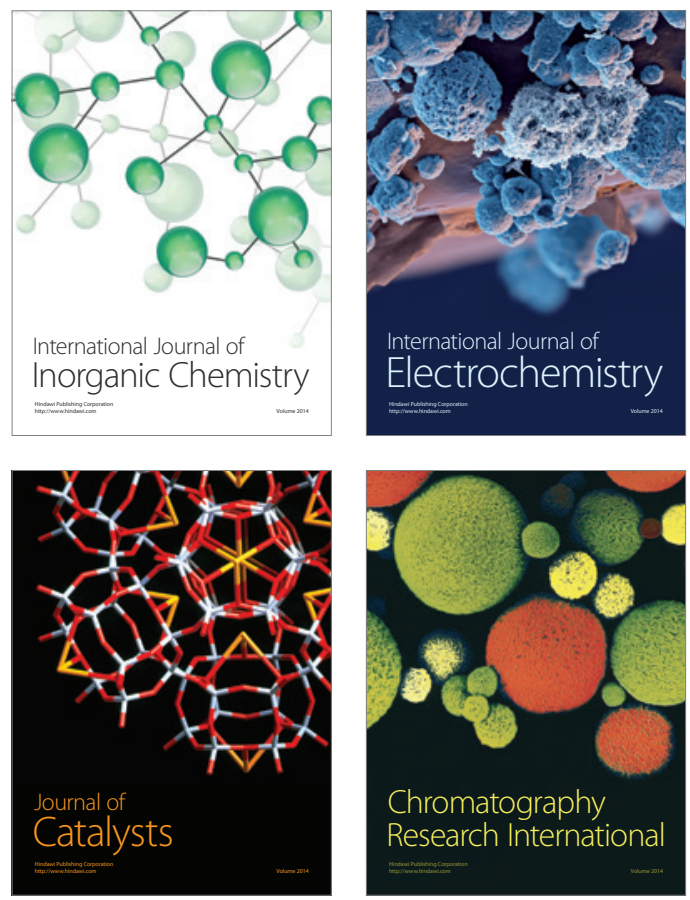
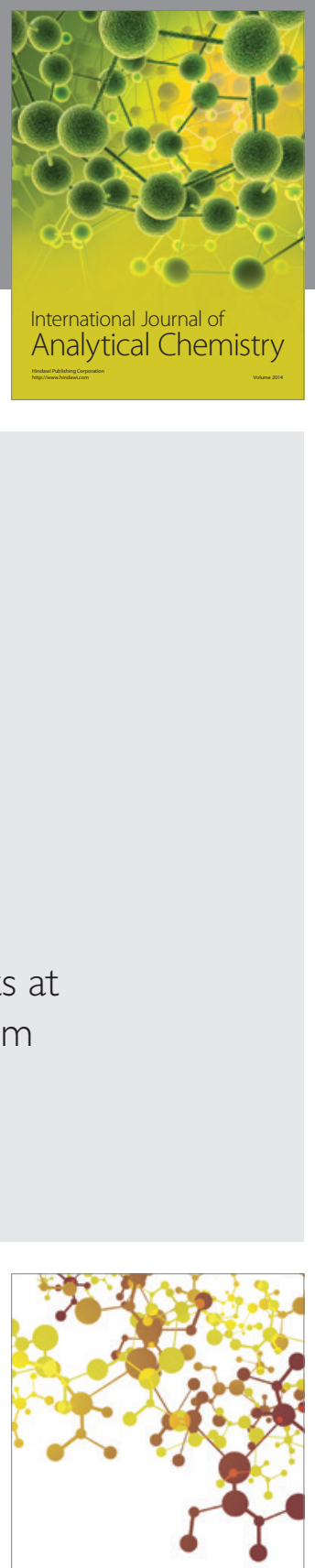

Journal of

Applied Chemistry
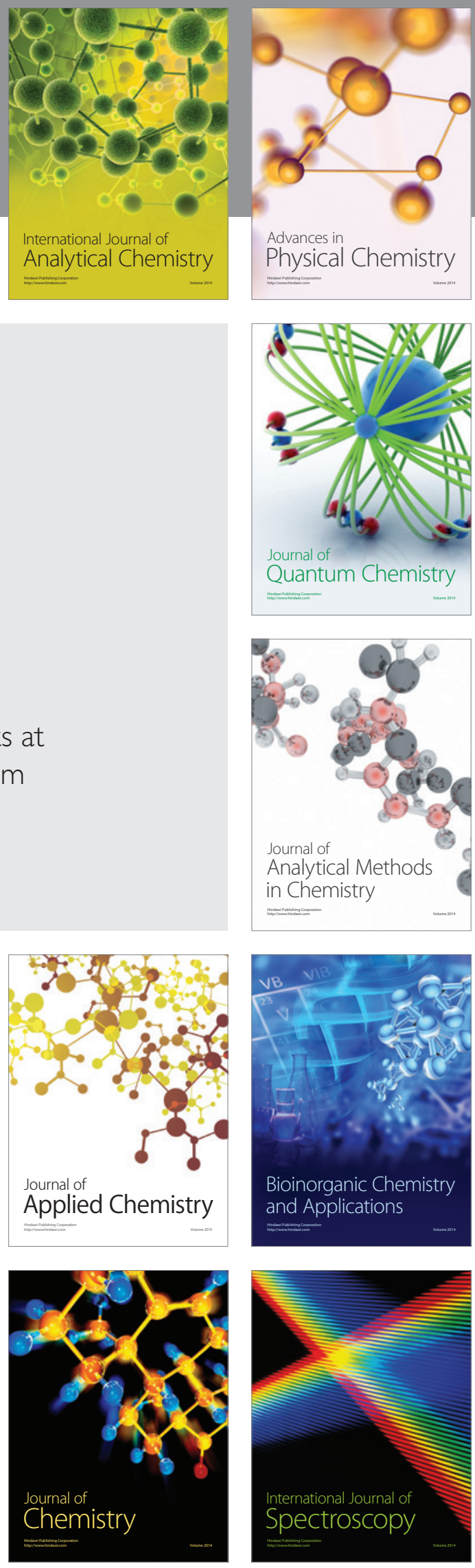